\title{
Eficiência da Madeira de Leucena (Leucaena leucocephala) Tratada com CCB Contra Cupins Xilófagos em Ensaio de Laboratório
}

\author{
Juarez Benigno Paes ${ }^{1}$, Rafael Rodolfo de Melo ${ }^{2}$, Rozileudo da Silva Guedes ${ }^{3}$, \\ Pierre Farias de Souza ${ }^{4}$ \\ ${ }^{1}$ Departamento de Ciências Florestais e da Madeira, Universidade Federal do Espírito Santo - UFES, \\ Jerônimo Monteiro/ES, Brasil \\ ${ }^{2}$ Instituto de Ciências Agrárias e Ambientais, Universidade Federal do Mato Grosso - UFMT, Sinop/MT, Brasil \\ ${ }^{3}$ Unidade Acadêmica de Engenharia Florestal, Universidade Federal de Campina Grande - UFCG, Patos/PB, Brasil \\ ${ }^{4}$ Programa de Pós-Graduação em Ciências Florestais, Universidade de Brasília - UnB, Brasília/DF, Brasil
}

\section{RESUMO}

A pesquisa objetivou analisar a eficiência do CCB-Óxido na resistência da madeira de leucena (Leucaena leucocephala) ao cupim Nasutitermes corniger, em ensaio de preferência alimentar. Foram colhidas 12 árvores com diâmetro de 6,0 a $12,0 \mathrm{~cm}$, tomado a 1,30 m do solo, em Patos, Paraíba. Os troncos foram seccionados em peças de $2,0 \mathrm{~m}$ e descascados. Foi utilizada uma solução de $2 \%$ de ingredientes ativos de CCB-Óxido. As peças foram submersas ( $50 \mathrm{~cm}$ da base) na solução de tratamento por 3, 6, 9 e 12 dias, e determinaram-se a penetração e a retenção do produto a 50 e $100 \mathrm{~cm}$ da base das peças. Foram retiradas amostras de $1,5 \times 1,5 \times 15,0 \mathrm{~cm}$ entre essas posições, sendo submetidas durante 45 dias ao ataque dos cupins. $\mathrm{O}$ tratamento conferiu melhorias na resistência da madeira de leucena ao cupim, tendo o tempo de tratamento de 12 dias promovido proteção adequada à madeira.

Palavras-chave: substituição de seiva, CCB, térmitas xilófagos, preferência alimentar.

\section{Efficiency of Leucaena leucocephala Wood Treated with CCB Against Xylophagous Termites Under Laboratory Assay}

\begin{abstract}
The aim of the present study was to analyze the efficiency of CCB-oxide on the resistance of Leucaena leucocephala wood to Nasutitermes corniger termite under food preference test. A total of 12 trees with diameters at breast height ranging from 6.0 to $12.0 \mathrm{~cm}$ were harvested in the municipality of Patos, Paraíba state, Brazil. The trunks were severed into $2.0 \mathrm{~m}$ parts and peeled. A solution of $2 \%$ active ingredients of CCB-oxide was used. The pieces were submerged $(50 \mathrm{~cm}$ from the base) in the treatment solution for 3, 6, 9 and 12 days and the penetration and retention of the solution was determined at 50 and $100 \mathrm{~cm}$ from the base. Samples of $1.5 \times 1.5 \times 15.0 \mathrm{~cm}$ were collected between these positions and submitted to termite attack for 45 days. The treatment has improved the resistance of Leucaena leucocephala wood to xylophagous termites, and the 12-day-long treatment promoted adequate protection to the wood.
\end{abstract}

Keywords: sap displacement, CCB, xylophagous termites, food preference assay. 
$179-8087.032813$

0980 (impresso) $)^{1 . ~ I N T R O D U C ̧ A ̃ O ~}$ 79-8087 (online)

As madeiras de boa resistência natural a xilófagos foram intensamente exploradas, tornando-se escassas em várias regiões. A escassez de espécies resistentes à deterioração biológica obrigou o homem a utilizar outras menos duráveis, principalmente aquelas de rápido crescimento, provenientes de reflorestamentos. A utilização dessas espécies tornou-se prática comum para os produtores rurais, porém estas necessitam de tratamento para melhorar sua vida útil (Paes et al., 2005).

A leucena (Leucaena leucocephala) é uma das leguminosas arbóreas de uso múltiplo, é produtiva e versátil, além de disponível em regiões tropicais (Shelton, 2001). Porém, a exemplo de uma série de outras espécies, produz madeira de baixa resistência a organismos xilófagos (Paes et al., 2007b, c).

Os térmitas (cupins) são, dentre os insetos, os mais severos agentes destruidores da madeira (Paes \& Vital, 2000). Dentre os cupins, os de solos, ou subterrâneos, são responsáveis pelos maiores volumes de perdas de madeira no mundo (Hunt \& Garratt, 1967; Richardson, 1993).

No Semiárido brasileiro, os cupins do gênero Nasutitermes são capazes de invadir, com sucesso, o meio urbano, atacando móveis e outros objetos construídos com madeira, como batentes de portas e janelas, e atacam, principalmente, madeiras empregadas nas estruturas das construções.

A resistência natural das madeiras pode ser melhorada por meio de tratamentos simples, que lhes proporcionam maior proteção, preservando, assim, os recursos florestais, o que é de fundamental importância ecológica e econômica, pois o alívio da pressão sobre as florestas remanescentes permite a formação de madeiras com maior dimensão, que podem ser utilizadas para fins mais nobres (Farias Sobrinho et al., 2005).

O método de substituição da seiva por transpiração radial se destaca pelo baixo custo das instalações, pela facilidade em tratar madeiras roliças e por conferir maior proteção na parte inferior das peças, que é a região mais vulnerável a ataques de xilófagos (Paes et al., 2005).

A eficiência de um tratamento preservativo é determinada pela distribuição, profundidade de penetração e quantidade de produto retido pela madeira (Hunt \& Garratt, 1967). Lepage (1986) afirmou que a penetração e a retenção dos produtos na madeira são os parâmetros que fornecem o verdadeiro grau de proteção das peças, sendo considerados de máxima importância no controle da qualidade do tratamento. No entanto, a eficácia do tratamento depende, além desses parâmetros, da toxidez do produto a organismos xilófagos (Carballeira Lopez \& Milano, 1986).

A American Society for Testing and Materials - ASTM D - 3345 (ASTM, 2005) descreve um ensaio de eficiência contra cupins. No método, os cupins subterrâneos são mantidos em recipientes contendo areia, em que pequenas amostras de madeira são expostas à população, de tamanho pré-determinado, por um período de quatro semanas. Ao término do ensaio, as amostras devem ser examinadas e $\mathrm{o}$ ataque avaliado com base em um critério subjetivo, que envolve a atribuição de notas. Conforme a Associação Francesa de Normalização (AFNOR - NFX - 41-539), citada por Lepage et al. (1986), a avaliação do ensaio deve envolver também a perda de massa porcentual da madeira.

Em seu trabalho, Supriana (1985) fez algumas críticas aos métodos normalizados pela ASTM D - 3345 e pela AFNOR - NFX - 41-539, ao considerar que, quando as madeiras são oferecidas em conjunto aos cupins, os resultados são mais realísticos. Assim, alguns pesquisadores, entre os quais, Abreu \& Silva (2000) e Paes et al. (2006, 2007c, 2010), vêm desenvolvendo e empregando ensaios de preferência alimentar de madeiras e derivados a cupins xilófagos do gênero Nasutitermes.

O objetivo desta pesquisa foi analisar a eficiência do CCB na melhoria da resistência da madeira de leucena (Leucaena leucocephala) ao térmita Nasutitermes corniger, em ensaio de preferência alimentar.

\section{MATERIAL E MÉTODOS}

\subsection{Coleta da madeira e preparo das soluções preservativas}

As árvores de leucena [Leucaena leucocephala (Lam.) de Wit.] foram coletadas nas proximidades do Viveiro Florestal do Campus da Universidade 
Federal de Campina Grande, em Patos, Paraíba. O município de Patos situa-se a $7^{\circ} 1^{\prime}$ latitude Sul, a $37^{\circ} 18^{\prime}$ de longitude Oeste e a 249,09 m de altitude, apresentando clima quente e seco durante a maior parte do ano. As plantas foram selecionadas em função do diâmetro, tomado a 1,30 m do solo (DAP), ao serem colhidas 12 árvores com DAP de 6,0 a $12,0 \mathrm{~cm}$. Após o corte das árvores, os fustes foram seccionados em peças de 2,00 m de comprimento e procedeu-se ao descascamento e à identificação das mesmas, conforme tratamento empregado.

Para o preparo das soluções preservativas, foi utilizado o CCB-Óxido que, segundo a Norma Brasileira Regulamentadora - NBR 9480 da Associação Brasileira de Normas Técnicas - ABNT (2009), tem como princípio ativo o cobre, o cromo e o boro.

O produto foi empregado na concentração $2 \%$ de ingredientes ativos. A solução foi preparada antes do abate das árvores, para se evitarem perdas de umidade das peças durante o preparo da solução. Após o preparo, a solução foi armazenada em tambor de 200 litros. Assim, para todos os tratamentos e quando da necessidade de reposições, foi empregada uma solução de mesma concentração. Antes das reposições, a solução era homogeneizada.

\subsection{Tratamento preservativo e amostragem dos moirões}

Para o tratamento das peças roliças e da madeira, empregou-se o método de substituição da seiva, por transpiração radial, conforme descrito por Paes et al. (2005) e Torres et al. (2011). Optou-se por este método pela simplicidade de manuseio e pela adequação ao meio rural. Os moirões permaneceram, conforme o tratamento, por 3, 6, 9 e 12 dias na solução preservativa. Foram empregados cinco moirões para cada tempo de tratamento.

Depois de tratadas, as peças foram empilhadas em local seco e ventilado, permanecendo nestas condições por 20 dias. Após a secagem, retiraram-se discos de $\pm 2,0 \mathrm{~cm}$ de espessura nas posições $0,5 \mathrm{e}$ $1,0 \mathrm{~m}$, região de afloramento em peças instaladas em cercas, posição 1, e meio do comprimento, posição 2, respectivamente (Figura 1 ).

\subsection{Avaliação da penetração e da retenção do CCB}

Para a penetração dos elementos cobre e boro, foram seguidas as recomendações da NBR 6232 da ABNT (2013), com algumas modificações sugeridas por Paes et al. (2005). Para a determinação da penetração de cobre, os discos foram pulverizados com solução de cromo azurol S, e para o boro, pulverizados com soluções de álcool polivinílico e iodo.

Os discos obtidos serviram para as reações reveladoras de ambos os elementos, pois, ao término da reação para o cobre, utilizou-se o lado oposto, para as reações do boro. As análises colorimétricas foram comparadas a um teste em branco, ou seja, em madeira não tratada.

Para a determinação da retenção do CCB, sortearam-se três peças de cada tratamento e retiraram-se discos suplementares nas posições 0,5 e 1,0 m (Figura 1). Dos discos obtidos, foram retiradas, em posições diametralmente opostas, quatro amostras de 1,5 × 1,5 × 2,0 cm (tangencial $\times$ radial $\times$ longitudinal), que receberam codificações de acordo com a posição no disco (Figura 2); sorteou-se, então, uma destas para a análise de retenção. Para a retenção, efetuou-se a digestão da madeira,

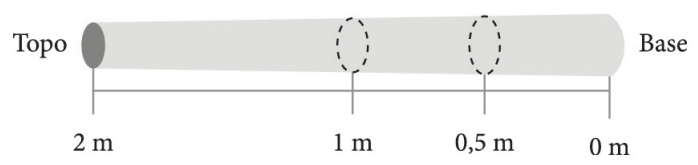

Figura 1. Posições nas peças das quais foram retirados os discos para as análises químicas.

Figure 1. Positions in pieces where the disks were taken to chemical analyses.
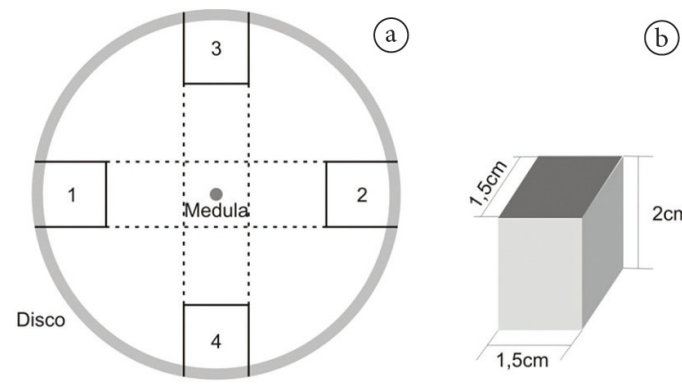

Figura 2. Posições (a) e dimensões (b) das amostras retiradas para as análises químicas.

Figure 2. Positions (a) and dimensions (b) of samples taken to the chemical analyses. 
conforme metodologia citada por Paes et al. (2005) e Torres et al. (2011).

As concentrações do cobre e do cromo foram obtidas por espectrometria de absorção atômica e a determinação do boro foi obtida por colorimetria, conforme descrito por Farias Sobrinho et al. (2005) e Torres et al. (2011). Com os dados das análises químicas e o volume de cada amostra, efetuaram-se os cálculos de retenção, ao empregar a Equação 1 (Paes et al., 2005).

$\mathrm{R}=\frac{\mathrm{F} \times \mathrm{L} \times \mathrm{Fd} \times 10^{-3}}{\mathrm{~V}}$

\section{Em que:}

$\mathrm{R}=$ Retenção do elemento na madeira, em $\mathrm{kg} / \mathrm{m}^{3}$;

$\mathrm{F}=$ Fator estequiométrico empregado para transformação dos elementos químicos para óxidos $\left(\right.$ cobre $\times 1,2518=\mathrm{CuO}$; cromo $\left.\times 1,9230=\mathrm{CrO}_{3}\right)$;

$\mathrm{L}=$ Leitura obtida do espectrofotômetro de absorção atômica, em mg/L;

$\mathrm{Fd}=$ Fator de diluição;

$\mathrm{V}=$ Volume das amostras utilizadas nas análises $\left(\mathrm{cm}^{3}\right)$.

\subsection{Ensaio de preferência alimentar com térmitas xilófagos}

Para a montagem do experimento, foram empregadas as amostras obtidas entre as posições 0,5 e 1,0 m (Figura 1), provenientes das peças sorteadas para a determinação da retenção. Para tanto, o torete obtido entre tais posições foi transformado em uma tábua contendo a medula, extraída no sentido radial, de 1,5 cm de espessura, pela remoção de duas costaneiras. As laterais da tábua, correspondentes ao local de retirada da amostra para o ensaio de retenção (Figura 2), foram transformadas em corpos de prova de $1,5 \times 1,5 \times 10,0 \mathrm{~cm}$ (radial $\times$ tangencial $\times$ longitudinal).

No ensaio, além da madeira de Pinus sp., utilizada como padrão de comparação, por recomendações da ASTM D - 3345 (ASTM, 2005), foram empregadas amostras de sumaúma [Ceiba pentandra (L.) Gaert.]. A sumaúma foi utilizada por ser uma madeira de baixa resistência ao ataque de cupins e ser utilizada em estruturas diversas.

A fim de facilitar a avaliação dos ensaios, as amostras foram lixadas para eliminar defeitos e tornar as faces planas e paralelas. Os corpos de prova obtidos foram secos à temperatura de $103 \pm 2{ }^{\circ} \mathrm{C}$, durante 48 horas, e pesados em uma balança de 0,01g de precisão, para a determinação da massa anidra dos mesmos.

Para a montagem do ensaio, as amostras foram dispostas em uma caixa de 250 litros, que continha uma camada de $\pm 10 \mathrm{~cm}$ de areia úmida. A caixa foi apoiada sobre quatro tijolos cerâmicos de oito furos, cada um destes disposto em uma bandeja de plástico de $30 \times 40 \times 5 \mathrm{~cm}$ contendo água e uma fina camada de óleo vegetal (para evitar a fuga dos cupins).

As amostras tratadas foram distribuídas segundo um delineamento em bloco casualizado, contendo cinco blocos, com três repetições cada, além das testemunhas (leucena não tratada, Pinus sp. e sumaúma), totalizando oito tratamentos estatísticos. As amostras tiveram a metade do seu comprimento fixada na areia, em um espaçamento de $8,0 \mathrm{~cm}$ (entre blocos) $\times 7,5 \mathrm{~cm}$ (entre tratamentos), que foram distribuídas em conjunto (três repetições) por meio de sorteio, conforme o tratamento empregado.

A colônia de cupins utilizada, da espécie Nasutitermes corniger (Motsch.), foi coletada em uma árvore de leucena e disposta numa grelha de $30 \times 40 \times 5 \mathrm{~cm}$, apoiada em quatro tijolos cerâmicos de oito furos, postos sobre a camada de areia contida na caixa. As amostras ficaram expostas à ação dos cupins durante 45 dias, em uma sala climatizada $\left(27 \pm 2{ }^{\circ} \mathrm{C}\right.$ e $75 \pm 5 \%$ de umidade relativa). Após o ensaio, as amostras foram secas, sob as condições já citadas, e pesadas para avaliar a porcentagem de perda de massa.

Para avaliar a eficiência do tratamento preservativo, foram computados a perda de massa e o desgaste provocado (Tabela 1). A perda de massa foi corrigida por meio de amostras submetidas às

Tabela 1. Avaliação do desgaste provocado pelos cupins na madeira.

Table 1. Evaluation of waste caused by termites on wood.

\begin{tabular}{lc}
\multicolumn{1}{c}{ Desgaste } & Notas \\
\hline Sadio, permitindo escarificações superficiais & 10 \\
Ataque superficial & 9 \\
Ataque moderado, havendo penetrações & 7 \\
Ataque intensivo & 4 \\
Falha, havendo ruptura dos corpos de prova & 0 \\
\hline Fonte: ASTM D - 3345 (ASTM, 2005).
\end{tabular}


mesmas condições de ensaio, porém sem a presença de cupins. Tais amostras foram utilizadas como fator de correção. Dessa maneira, garantiu-se que as perdas observadas pudessem, de fato, serem atribuídas ao ataque dos cupins xilófagos e não a outros fatores operacionais.

\subsection{Avaliação dos resultados}

Para o tratamento das peças, foi utilizado um delineamento inteiramente casualizado, contendo quatro tempos de tratamento $(3,6,9,12$ dias $)$ e cinco repetições. Os valores de penetração dos elementos cobre e boro foram avaliados em cinco peças tratadas e, para a análise da retenção do CCB, foram sorteadas três peças de cada tratamento. A penetração e a retenção foram determinadas em duas posições nas peças tratadas (Figura 1).

Os valores de penetração e retenção foram comparados em função da média aritmética e, para comparar a resistência da madeira tratada ao térmita Nasutitermes corniger, foi empregado o delineamento em blocos casualisado, em que foram analisadas as seguintes situações: quatro tempos de tratamento $(3,6,9,12$ dias), além de amostras de madeiras de leucena provenientes de peças não tratadas, madeira de pinus e madeira de sumaúma, com cinco blocos e três repetições por bloco (amostras provenientes de três peças de cada madeira).

Os dados de perda de massa foram transformados em arcsen [raiz (perda de massa/100)] e o desgaste causado pelos térmitas, em raiz [ (nota ou dias) $+0,5]$.
A transformação dos dados (Steel \& Torrie, 1980) foi necessária para homogeneizar as variâncias. Empregou-se o teste de Tukey ( $\mathrm{p}>0,05)$ para as fontes de variação detectadas como significativas pelo teste de $\mathrm{F}(\mathrm{p} \leq 0,05)$.

\section{RESULTADOS E DISCUSSÃO}

\subsection{Avaliação da qualidade do tratamento da madeira de leucena}

A penetração de cobre e boro foi maior na posição 1 , tomada a $0,5 \mathrm{~m}$ da base dos moirões (Tabela 2). Isto ocorreu porque o método de tratamento empregado confere maior penetração e retenção na terça parte inferior das peças (madeira em contato direto com a solução de tratamento), o que é vantajoso, uma vez que esta é a posição mais propícia ao desenvolvimento de xilófagos em peças instaladas no solo, conforme citado por Farias Sobrinho et al. (2005), Paes et al. (2005) e Torres et al. (2011). Observou-se um incremento da penetração a partir do tempo de tratamento de três dias.

Uma profundidade de penetração de substâncias preservativas superior a $10 \mathrm{~mm}$ é suficiente para garantir uma boa eficiência das peças em serviço (Paes et al., 2005). Penetrações satisfatórias de cobre foram obtidas para os tempos de 6, 9 e 12 dias, porém apenas para a região de afloramento, posição 1, tomada a $0,5 \mathrm{~m}$ da base dos toretes. Uma penetração satisfatória de boro (agente inseticida) foi obtida para todos os tempos de tratamento e posições nas peças.

Tabela 2. Penetrações de cobre e boro, e retenção do CCB nas peças tratadas de leucena (Leucaena leucocephala).

Table 2. Copper and boron penetrations and CCB retention in Leucaena leucocephala treated pieces.

\begin{tabular}{|c|c|c|c|c|}
\hline \multirow{3}{*}{$\begin{array}{c}\text { Tempo } \\
\text { (dias) }\end{array}$} & \multicolumn{2}{|c|}{ Penetração de Cobre (mm) } & \multicolumn{2}{|c|}{ Penetração de Boro (mm) } \\
\hline & \multicolumn{4}{|c|}{ Posições nas Peças Tratadas } \\
\hline & 1 (Base) & 2 (Meio) & 1 (Base) & 2 (Meio) \\
\hline 3 & 4,90 & 4,30 & 16,85 & 12,05 \\
\hline 6 & 11,55 & 7,85 & 20,70 & 16,75 \\
\hline 9 & 9,80 & 5,15 & 24,15 & 19,75 \\
\hline 12 & 10,90 & 8,95 & 26,75 & 17,80 \\
\hline \multirow{3}{*}{$\begin{array}{c}\text { Tempo } \\
\text { (dias) }\end{array}$} & \multicolumn{4}{|c|}{ Retenção do CCB (kg i.a.m-3) } \\
\hline & \multicolumn{4}{|c|}{ Posições nas Peças Tratadas } \\
\hline & \multicolumn{2}{|c|}{1 (Base) } & \multicolumn{2}{|c|}{2 (Meio) } \\
\hline 3 & \multicolumn{2}{|c|}{14,43} & \multicolumn{2}{|c|}{7,25} \\
\hline 6 & \multicolumn{2}{|c|}{12,10} & \multicolumn{2}{|c|}{9,66} \\
\hline 9 & \multicolumn{2}{|c|}{16,61} & \multicolumn{2}{|c|}{10,94} \\
\hline 12 & \multicolumn{2}{|c|}{25,75} & \multicolumn{2}{|c|}{15,91} \\
\hline
\end{tabular}


As retenções de CCB foram superiores a $6,5 \mathrm{~kg}$ de i.a. $\mathrm{m}^{-3}$ de madeira (Tabela 2), que é a mínima exigida pela NBR 9480 da ABNT (2009) para peças de madeira que ficarão em contato com o solo. Desta forma, o tempo de tratamento de seis dias proporcionou penetrações e retenções adequadas, para o uso em cercas e em outras benfeitorias em que a madeira entra em contato direto com o solo. Em Paes et al. (2007a), há informações detalhadas sobre o tratamento das peças e comparações entre as médias para os valores de penetração e retenção do CCB, nas peças de leucena tratada.

\subsection{Avaliação da eficiência do tratamento da madeira de leucena}

$\mathrm{Na}$ Tabela 3, consta o resumo das análises de variância para os valores de perda de massa e de desgaste para a madeira de leucena submetida ao ataque de cupins da espécie Nasutitermes corniger. Observa-se que o tempo de tratamento teve efeito significativo para a perda de massa e o desgaste. As médias da perda de massa e de desgaste foram comparadas pelo teste de Tukey (Tabela 4).

A madeira de Pinus sp., empregada para permitir a comparação com outros trabalhos em que esta madeira é utilizada (ASTM, 2005), teve perda de massa de 13,80\% e desgaste (nota) de 5,67 (Tabela 4), quando submetida a cupins, tendo comportamento semelhante ao da madeira que ficou três dias na solução de tratamento, enquanto a sumaúma foi completamente destruída.

Os valores contidos na Tabela 4 indicaram que os cupins atacaram, em alguns casos, severamente a madeira (amostras de madeira de leucena não tratadas ou submetidas a três dias de tratamento). Diversamente, em outros casos, não houve ataque ou este foi superficial (12 dias de tratamento) ou esteve entre superficial e moderado (seis e nove dias de tratamento), conforme a classificação apresentada na Tabela 1. Em função dos valores de perda de massa e de desgaste obtidos pela madeira tratada, quando comparada à não tratada, justifica-se o tratamento preservativo, conforme já observado por Paes et al. (2008), ao avaliarem a resistência da madeira de leucena tratada contra o ataque de fungos e cupins xilófagos.

Com o intuito de melhor analisar os dados, empregaram-se relações entre o tempo em que a madeira permaneceu na solução de tratamento

Tabela 3. Resumo das análises de variância da perda de massa e do desgaste. Dados transformados em arcsen [raiz (perda de massa/100)] ou raiz (nota $+0,5)$.

Table 3. Resume of variance analysis of loss of mass and of waste. Data processed in arcsine [root (loss of mass/100)] or root (note +0.5$)$.

\begin{tabular}{cccc|} 
Fontes de Variação & Graus de Liberdade & Quadrados Médios \\
\cline { 3 - 4 } & 4 & $0,81 \times 10^{-2 \mathrm{~ns}}$ & $0,25 \times 10^{-1 \mathrm{~ns}}$ \\
Bloco & 4 & $0,66^{* *}$ & $3,53^{* *}$ \\
Tempo & 66 & $0,38 \times 10^{-1}$ & 0,23 \\
\hline Resíduos & 74 & 5,22 & 29,49 \\
\hline Total & & Pesda de Massa & \\
\hline
\end{tabular}

${ }^{* *}$ significativo a $1 \%$ de probabilidade; ${ }^{\mathrm{n}}$ não significativo a $5 \%$ de probabilidade.

Tabela 4. Perda de massa e desgaste causados nas peças tratadas de leucena (Leucaena leucocephala) pelos térmitas. Table 4. Loss of mass and waste caused in Leucaena leucocephala treated pieces by termites.

\begin{tabular}{ccc}
$\begin{array}{c}\text { Tempo de Tratamento } \\
\text { (dias) }\end{array}$ & $\begin{array}{c}\text { Perda de Massa } \\
(\%)\end{array}$ & $\begin{array}{c}\text { Desgaste } \\
\text { (Notas) }\end{array}$ \\
\hline $0^{*}$ & $37,79 \mathrm{a}$ & $3,91 \mathrm{c}$ \\
3 & $12,45 \mathrm{~b}$ & $6,59 \mathrm{~b}$ \\
6 & $5,53 \mathrm{bc}$ & $8,59 \mathrm{ab}$ \\
9 & $9,52 \mathrm{bc}$ & $7,91 \mathrm{ab}$ \\
\hline 12 & $1,20 \mathrm{c}$ & $9,63 \mathrm{a}$ \\
\hline Pinus sp. & 13,80 & 5,67 \\
\hline
\end{tabular}

As médias seguidas pela mesma letra, em cada parâmetro avaliado, não diferem estatisticamente pelo teste de Tukey $(\mathrm{p} \geq 0,05)$. ${ }^{*}$ Madeira de leucena não submetida ao tratamento preservativo. 
e a perda de massa (Figura 3), e entre o tempo e o desgaste (nota) causado pelos cupins na madeira (Figura 4).

Observa-se, na Figura 3, que a perda de massa decresceu com o incremento do tempo de tratamento da madeira; porém, notou-se dispersão na maioria dos valores, exceção feita para o tempo de 12 dias, em que os valores foram praticamente coincidentes. Isto indicou que, para as condições em que a madeira foi tratada, o tempo de 12 dias foi o suficiente para garantir uma boa resistência da madeira a cupins.

Os tempos de tratamento de 6 e 9 dias tiveram comportamento semelhante, tendo suas perdas de massa médias variando entre 5 e 18\%, enquanto, para o tempo de 3 dias, as médias variaram de 10 a $18 \%$. Estes valores indicam que a madeira tratada teve uma perda de massa inferior à obtida pela madeira não tratada, a qual teve perda de massa média de variando de 33 a $45 \%$.

Comportamento semelhante, porém inverso, foi observado para o desgaste (nota) causado

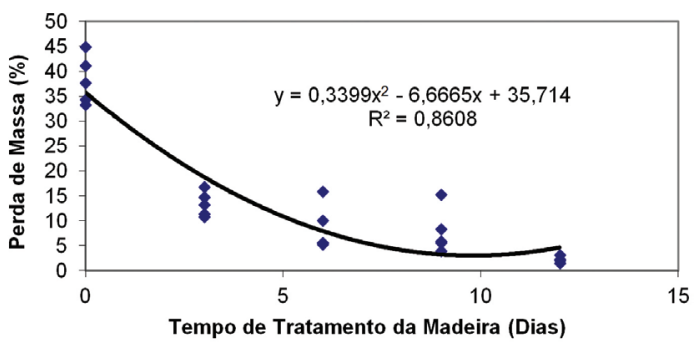

Figura 3. Relação entre o tempo de tratamento da madeira e a perda de massa causada pelos cupins.

Figure 3. Relationship between the wood treatment time and the mass loss caused by termites.

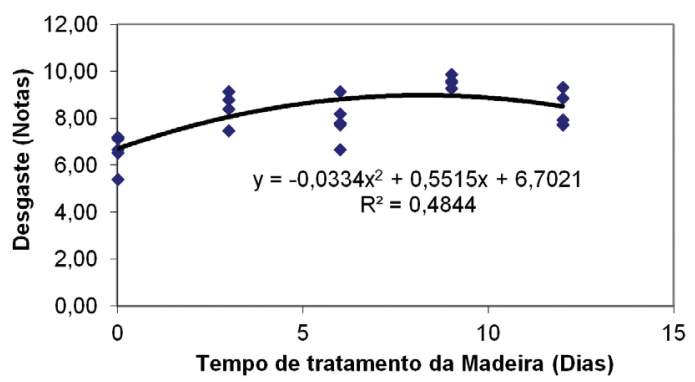

Figura 4. Relação entre o tempo de tratamento da madeira e o desgaste causado pelos cupins.

Figure 4. Relationship between the wood treatment time and the waste caused by termites. pelos cupins na madeira (Figura 4). Para este caso, observa-se uma tendência de inflexão da curva a partir de 9 dias de exposição da madeira ao tratamento, indicando que, a partir deste tempo de tratamento, as notas de desgaste teriam um decréscimo. Porém, a curva não se ajustou bem aos dados, tendo um ajuste de apenas $48 \%$ em relação aos valores avaliados. Isto provavelmente pode ter ocorrido em função da avaliação subjetiva, a qual é atribuída por meio de notas fornecidas, neste caso, por cinco avaliadores.

\section{CONCLUSÕES}

A penetração de cobre e boro, de modo geral, decresceu da base para o meio do comprimento das peças tratadas. A retenção do $\mathrm{CCB}$, geralmente, esteve associada à penetração dos elementos cobre e boro na madeira tratada.

O número de dias de permanência da madeira na solução preservativa influenciou os resultados. Os maiores tempos de tratamento proporcionaram uma maior proteção à madeira.

O tempo de tratamento de 12 dias, em função da penetração e da retenção adequadas do CCB nas peças, seria o suficiente para garantir um bom desempenho da madeira tratada em serviço.

No geral, o tratamento preservativo conferiu melhoria na resistência da madeira de leucena frente ao ataque de Nasutitermes corniger, que é um dos térmitas de maior ocorrência no Semiárido brasileiro.

\section{STATUS DA SUBMISSÃO}

Recebido: 02 mar., 2013

Aceito: 12 ago., 2013

Publicado: 28 ago., 2014

\section{AUTOR(ES) PARA CORRESPONDÊNCIA}

\section{Juarez Benigno Paes}

Departamento de Ciências Florestais e da

Madeira, Universidade Federal do Espírito

Santo - UFES, CEP 29550-000, Jerônimo

Monteiro, ES, Brasil

e-mail: jbp2@uol.com.br 


\section{REFERENNCIAS}

Abreu RLS, Silva KES. Resistência natural de dez espécies madeireiras da Amazônia ao ataque de Nasutitermes macrocephalus (Silvestri) e N. surinamensis (Halmgrem) (Isoptera: Termitidae). Revista Árvore 2000; 24(2): 229234.

American Society for Testing and Materials. ASTM D3345: Standard method for laboratory evaluation of wood and other cellulosic materials for resistance to termite. Philadelphia; 2005. Annual Book of ASTM Standard.

Associação Brasileira de Normas Técnicas. NBR 6232: Penetração e retenção de preservativos em madeira tratada sob pressão. Rio de Janeiro; 2013.

Associação Brasileira de Normas Técnicas. NBR 9480: Peças roliças preservadas de eucalipto para construções rurais - requisitos. Rio de Janeiro; 2009.

Carballeira Lopez GA, Milano S. Avaliação da durabilidade natural da madeira de e de produtos usados na sua proteção. In: Lepage ES, coordenador. Manual de preservação de madeira. São Paulo: IPT; 1986. v. 2, p. 473-521.

Farias DW So, Paes JB, Furtado DA. Tratamento preservativo da madeira de algaroba (Prosopis juliflora (Sw) D.C.), pelo método de substituição de seiva. Cerne 2005; 11(3): 225-236.

Hunt GM, Garrat GA. Wood preservation. 3rd ed. New York: McGraw Hill; 1967.

Lepage ES. Preservativos e sistemas preservativos. In: Lepage ES, coordenador. Manual de preservação de madeiras. São Paulo: IPT; 1986. v. 1, p. 279-342. Volume 1.

Lepage ES, Geraldo FC, Zanotto PA, Milano S. Métodos de tratamento. In: Lepage ES, coordenador. Manual de preservação de madeiras. São Paulo: IPT; 1986. v. 2, p. 343-419. Volume 2.

Paes JB, Vital BR. Resistência natural da madeira de cinco espécies de eucalipto a cupins subterrâneos em testes de laboratório. Revista Árvore 2000; 24(1): 1-6.

Paes JB, Moreschi JC, Lelles JG. Avaliação do tratamento preservativo de moirões de Eucalyptus viminalis Lab. e de bracatinga (Mimosa scabrella Benth.) pelo método de substituição de seiva. Ciência Florestal 2005; 15(1): 75-86.
Paes JB, Ramos IEC, Farias DW So. Eficiência do CCB na resistência da madeira de algaroba (Prosopis juliflora (Sw) D.C.) a cupins subterrâneos (Nasutiternes corniger Motsch.) em ensaio de preferência alimentar. Ambiência 2006; 2(1): 51-64.

Paes JB, Guedes RS, Lima CR, Cunha MCL. Tratamento preservativo de peças roliças de leucena (Leucaena leucocephala (Lam.) De Wit.) pelo método de substituição da seiva. Revista de Ciências Agrárias 2007a; (47): 231-246.

Paes JB, Melo RR, Lima CR. Resistência natural de sete madeiras a fungos e cupins xilófagos em condições de laboratório. Cerne 2007b; 13(2): 160-169.

Paes JB, Melo RR, Lima, CR, Oliveira, E. Resistência natural de sete madeiras ao cupim subterrâneo (Nasutitermescorniger Motsch.) em ensaio depreferência alimentar. Revista Brasileira de Ciências Agrárias 2007c; 2(1): 57-62.

Paes JB, Melo RR, Lima CR, Guedes RS. Eficiência do tratamento preservativo na resistência da madeira de leucena (Leucaena leucocephala (Lam.) de Wit.) a organismos xilófagos. Revista Forestal Venezolana 2008; 52(1): 85-91.

Paes JB, Fonsêca CMB, Lima CR, Souza AD. Eficiência do óleo de candeia na melhoria da resistência da madeira de sumaúma a cupins. Cerne 2010; 16(2): 217 225 .

Richardson BA. Wood preservation. 2nd ed. London: E \& FN SPON; 1993.

Shelton HM. Potenciais e limitações de Leucaena spp. para uso em sistemas silvipastoris. In: Carvalho MM, Alvin MJ, Carneiro JC, editores. Sistemas agroflorestais pecuários: opções de sustentabilidade para áreas tropicais e subtropicais. Juiz de Fora: FAO, Embrapa; 2001. cap. 21, p. 379-398.

Steel RGD, Torrie JH. Principles and procedures of statistic: a biometrical approach. 2. ed. New York: McGraw-Hill; 1980.

Supriana N. Notes the resistance of tropical wood against termites. Stockholm: The International Research Group on Wood Preservation; 1985. Doc. IRG/WP, 1249.

Torres PMA, Paes JB, Lira JA Fo, Nascimento JWB. Tratamento preservativo da madeira juvenil de Eucalyptus camaldulensis Dehnh. pelo método de substituição de seiva. Cerne 2011; 17(2): 275-282. 